\title{
2-D Inversion of magnetic data and gravity modelling for characterization of the basement adjacent to the Sergipe-Alagoas basin
}

Priscilla Alvarez Araújo* (CPGG/UFBA), Alanna Costa Dutra (CPGG/LFNA/IF-UFBA)

\begin{abstract}
Copyright 2019, SBGf - Sociedade Brasileira de Geofísica
This paper was prepared for presentation during the $16^{\text {th }}$ International Congress of the Brazilian Geophysical Society held in Rio de Janeiro, Brazil, 19-22 August 2019.

Contents of this paper were reviewed by the Technical Committee of the $16^{\text {th }}$ International Congress of the Brazilian Geophysical Society and do not necessarily represent any position of the SBGf, its officers or members. Electronic reproduction or storage of any part of this paper for commercial purposes without the written consent of the Brazilian Geophysical Society is prohibited.
\end{abstract}

\begin{abstract}
The purpose of this work is to perform a two-dimensional magnetic inversion to obtain information about the magnetic susceptibility contrast, and gravity models, obtaining depth and volume of the sources located in the basement of the transition zone between the Pernambuco-Alagoas domain and the Sergipano Belt. Magnetic data processing was performed to interpret geological contacts, source's edge detection and mapping of folds and shear zones. In the results of the inversion, a magnetic source was found in the Rio Coruripe domain between 9 and $21 \mathrm{~km}$ in depth with a magnetic susceptibility of 0.0079 (SI) and another in the Pernambuco-Alagoas domain between 7.5 and $9 \mathrm{~km}$ with a susceptibility of 0.0077 (SI). The depth of the basement was obtained through spectral analysis, whose base was found at $37.7 \mathrm{~km}$ and top at 709 meters. The gravity models were created with the purpose to verify the information obtained by the magnetic inversion and spectral analysis.
\end{abstract}

\section{Introduction}

The Sergipe-Alagoas basin is located at the continental margin of the Brazilian northeast region, with an area of approximately $45.000 \mathrm{~km}^{2}$ and has a good potential for oil exploration and production in ultra-deep waters, which makes important the development of researches in this area.

In this work, inversions of magnetic data and gravity modelling was performed with the purpose to obtain information about the sources in the transition zone between the Pernambuco-Alagoas domain and the Sergipano Belt, which is located at the southern Borborema Province (NEVES et al., 2016). The Borborema Province corresponds to the northeast Folding Region, which is characterized by the presence of extensive transcurrent shear zones and granite-gneiss terrains (DOS SANTOS et al., 1998). The PernambucoAlagoas domain, where was found one of the magnetic sources of this work, is limited south-southeast by the Rio Coruripe domain through the contractional shear zone Palmeira dos Índios, which consists predominantly of orthogneisses (BRITO NEVES et al., 1982), brasilianoage granitoids of varied compositions and sinistral shear zones. The Sergipano Belt is composed by the Rio Coruripe, Macururé, Canindé and Marancó-Poço Redondo domains and by basement rocks exposed in the Jirau do Ponciano gneisseic dome (NEVES et al., 2016). The Rio Coruripe domain, where another magnetic source was found, is limited south-southeast by the Canindé domain through the Belo Monte Jeremoabo shear zone. It is composed by paragneisses and metaultramafic rocks intercalated with banded iron formations (MENDES et al., 2007), which can justify the magnetic properties of the place. The basement of the area is composed by supracrustal rocks with granulite facies along supracrustal rocks with amphibolite facies.

\section{Method}

To obtain information about the magnetic susceptibility, depth and volume of the sources, a bidimensional inversion of the magnetic data was performed using a software called MAG2DATA, developed by Stocco et al. (2009), whose code considers the subsurface as being made of 2-D horizontal prisms orthogonal to the profiles, with a constant magnetic characteristic in each prism. The inversion is performed in two steps: calculation of the direct problem and solution of the inverse problem. In that way, if the computation of the direct problem is performed in each prism at each measured point, the result is a kernel matrix with the same number of rows as measuring points and the same number of columns as discretization prisms (STOCCO et al., 2009). The method of inversion is based on the principle of compact inversion (LAST and KUBIK, 1983) that involves minimizing the area of the source body, which means maximizing its compactness, with the purpose to obtain the best result at each iteration.

The gravity modelling was performed at the software GMSYS, which is based on the method of bidimensional modelling developed by Talwani et al. (1959). In this method, lithological structures are drawn in shapes of polygons and the volume of the source is obtained by the calculation of the gravitational attraction caused by each vertex of the polygon, where the density is constant in every source body. The purpose of the models is to verify the information obtained by the magnetic inversion and spectral analysis results.

To perform the inversion, a regional-residual separation of the magnetic data was made by upward continuation, where the removal of information is realized from a value of depth, obtained through the analysis of the shape of the radially average power spectrum of the data, known as spectral analysis. For the interpretation of geological contacts and mapping of folds and shear zones, a phase transformation of the signal was performed, called Total Horizontal Gradient (THG), which allows edge detections 
of source bodies, that provided the identification of the best places to extract the magnetic and gravity profiles.

\section{Results}

The aeromagnetic data used in this work were granted by CPRM (Company of Research in Mineral Resources), in which two aeromagnetic surveys were realized, with a flight line spacing of 500 meters in the N-S direction and $10 \mathrm{~km}$ between the control lines in the E-S direction. The magnetic data processing was performed in the software Oasis Montaj, and a regional-residual separation process was required to obtain the subject of interest of this study. To do so, an upward continuation was performed, where the estimated depth value used in this process was obtained through radially average power spectrum analysis of the magnetic data. The analysis was applied on polygons with $25 \mathrm{~km}^{2}, 50 \mathrm{~km}^{2}, 100 \mathrm{~km}^{2}, 150 \mathrm{~km}^{2}$ and $200 \mathrm{~km}^{2}$ taken from the total field anomaly map and performed on a program in Matlab code. Since the main purpose of this work is to characterize the basin's basement, the regional-residual separation removed all of the information below and on top of it. In that way, the spectral analysis found depths for the base of the basement $\left(\mathbf{Z}_{\mathbf{b}}\right)$ and for its top $\left(\mathbf{Z}_{\mathbf{t}}\right)$, described on Table 1.

Table 1: Depths of base and top of the basement found by spectral analysis.

\begin{tabular}{|c|c|c|}
\hline Polygons & $\mathbf{Z}_{\mathbf{t}}(\mathbf{k m})$ & $\mathbf{Z}_{\mathbf{b}}(\mathbf{k m})$ \\
\hline $200 \mathrm{~km}^{2}$ & -0.722 & -36.0 \\
\hline $150 \mathrm{~km}^{2}$ & -0.709 & -37.7 \\
\hline $100 \mathrm{~km}^{2}$ & -0.848 & -37.0 \\
\hline $50 \mathrm{~km}^{2}$ & -0.913 & -22.2 \\
\hline $25 \mathrm{~km}^{2}$ & -0.632 & -3.4 \\
\hline
\end{tabular}

Since the greatest depth found for the basement's base was $37.7 \mathrm{~km}$, this was the depth chosen to carry out the regional-residual separation. Information above 709 meters (depth of the top) was also removed, because shallower sources were considered as noise. Thus, a residual magnetic field anomaly map was obtained, where the profiles used to perform the magnetic inversion were extracted from, as shown in figure 1. To determine the location of these profiles, the total horizontal gradient (THG) was applied to the residual magnetic field data, which allowed a better visualization of the source's edges, delimitating the contacts between the source bodies. It was also possible to identify folds in the Rio Coruripe domain's region, due to its location at the northeast folding region of the Borborema Province. Contractional shear zones, such as the Belo Monte Jeremoabo shear zone, indicated by the triangles in figure 2 , and a sinistral shear zone, indicated by the arrows, located above the Pernambuco-Alagoas source, were also found. It's also possible to notice the presence of the Jirau do Ponciano gneissic dome, located below the Rio Coruripe source.

The THG map shown in figure 2 also allowed the interpretation of the source's strike-dip directions, where the Rio Coruripe source is at the NW-SE direction, with a SW-NE dip direction and the Pernambuco-Alagoas source is at the NE-SW direction, with a SE-NW dip direction.

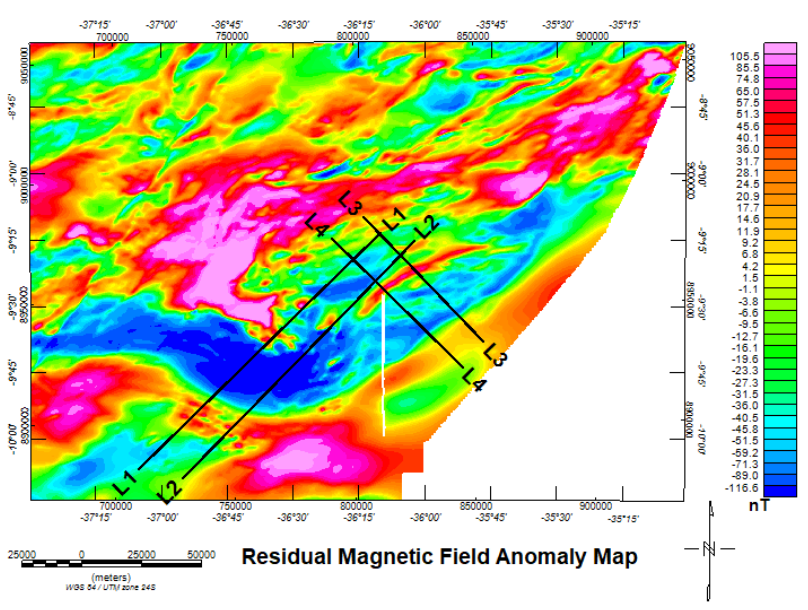

Figure 1: Residual magnetic field anomaly map, with profiles extracted for the magnetic inversion.

The L1 and L2 profiles shown in figure 1 are referent to the Rio Coruripe source, while the L 3 and L4 profiles are referent to the Pernambuco-Alagoas source.

To perform the inversion, it was necessary to insert the entry parameters referent to the features of the earth's magnetic field of the time the data was obtained. The intensity of the magnetic field used was $25.380 \mathrm{nT}$, the field's inclination was $-27.3^{\circ}$ and its declination (magnetic north) was $-22.7^{\circ}$. These values were used for both the Rio Coruripe and Pernambuco-Alagoas sources inversion.

The inversion is performed by inserting parameters related to the building of the prisms' matrix that will represent the subsurface, such as the number of prisms in the $X$ (rows) and $Z$ (columns) directions, and the thickness and susceptibility contrast for each prism. Since the inversion procedure is an optimization process, it was also necessary to insert a maximum number of iterations that the software will perform until the solution was stabilized. As a result, the software will deliver the depth and magnetic susceptibility of the prisms, which represents the sources in subsurface.

\section{Rio Coruripe source}

For the inversion of the L1 profile referent to the Rio Coruripe source, 30 prisms were inserted along the Xdirection (rows) and 5 prisms were inserted along the Zdirection (columns), with a thickness of 6.000 meters for each prism. The maximum number of iterations was 20 , with a susceptibility contrast of 0.07 for each prism. The result of the inversion for the L1 profile is shown in figure 3 , where a magnetic source, highlighted by the red rectangle drawn by hand, was found between 9.000 and 21.000 meters in depth, and its greatest lateral extension was found at 15.000 meters, with a magnetic susceptibility of $0.0055704(\mathrm{SI})$. The error between the calculated and observed data was $4.48 \%$. 


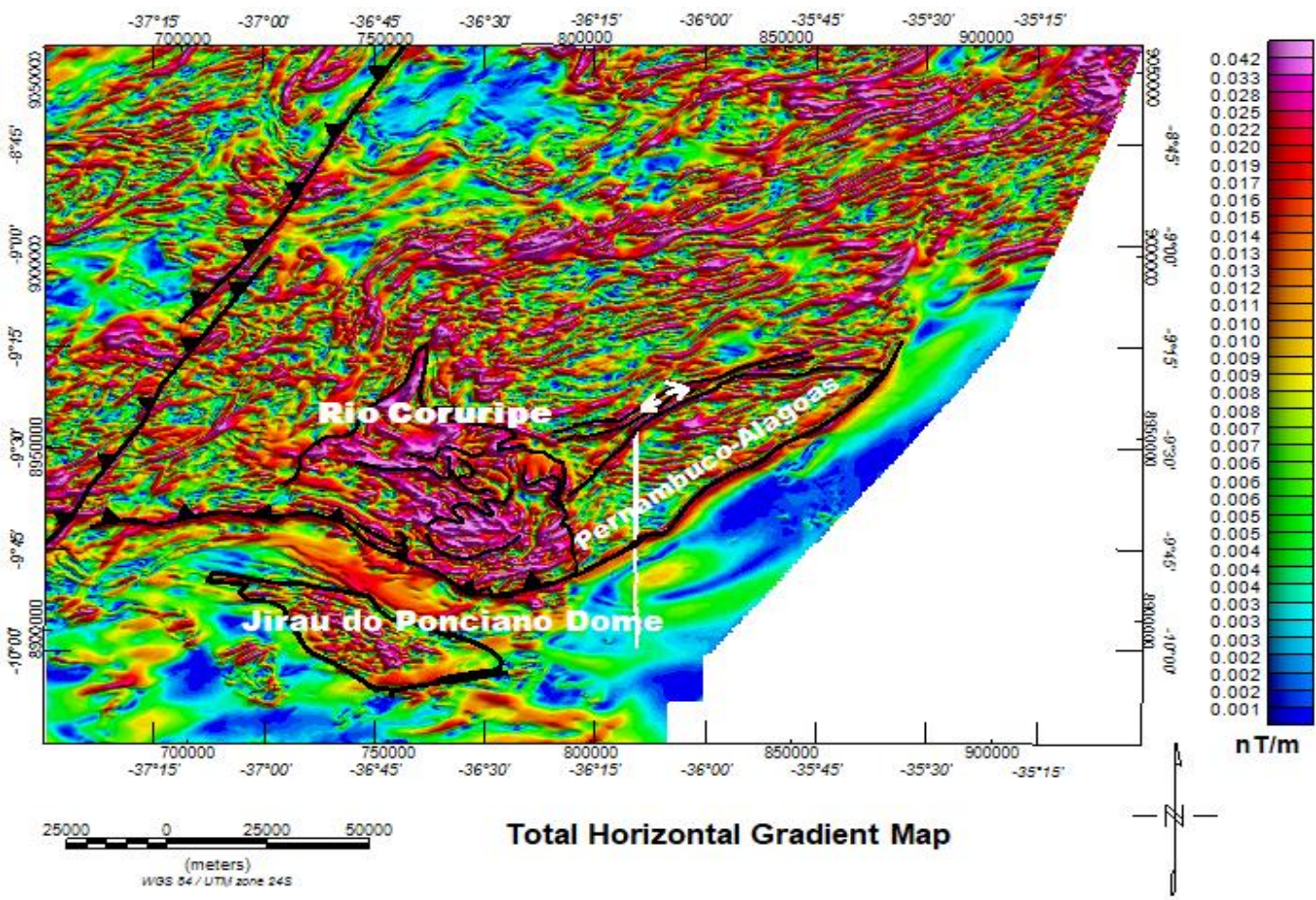

Figure 2: Total horizontal gradient map (THG), highlighting the region's sources and lineaments.

For the inversion of the $\mathrm{L} 2$ profile, also referent to the Rio Coruripe source, 30 prisms were inserted along the Xdirection and 5 prisms were inserted along the Zdirection, with a thickness of 7.500 meters for each prism. The maximum number of iterations was also 20, with a susceptibility contrast of 0.1 for each prism. The result of the inversion for the L2 profile is shown in figure 4 , where the depth of the source was found between 11.250 and 18.750 meters, with a magnetic susceptibility of 0.0079577 (SI). The error between the calculated and observed data was $3.28 \%$.
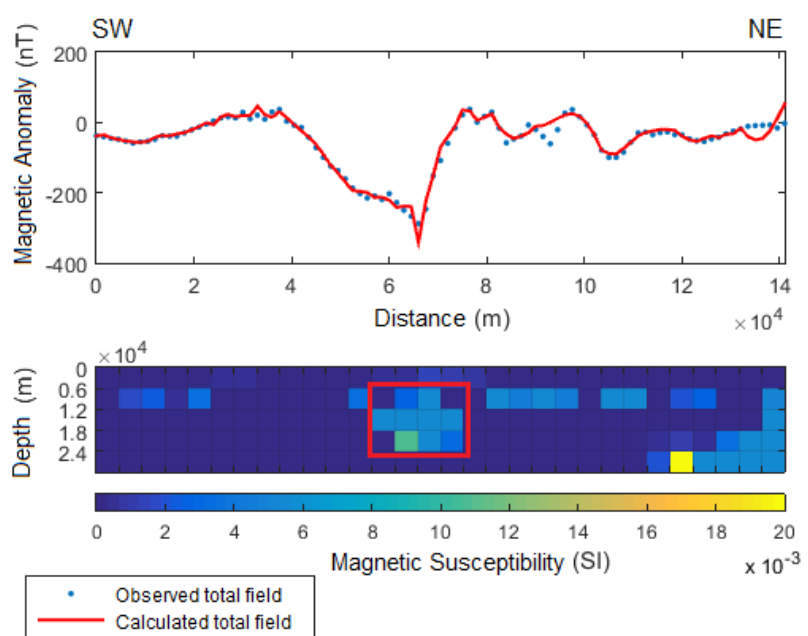

Figure 3: Result of the magnetic inversion for the $L 1$ profile, highlighting the Rio Coruripe source.
In that way, we can assume that the Rio Coruripe source is located between 9.000 and 21.000 meters, where its superior and inferior boundaries are narrower and its biggest lateral extension is located at 15.000 meters in depth. The source has an estimated magnetic susceptibility of approximately 0.0079 (SI) and outcrops into the surface, since we can see that there are prisms with a smaller magnetic susceptibility above the source in figure 3 , that indicates that the source's magnetic susceptibility is smaller at the surface and enhances until the depth found by the inversion.
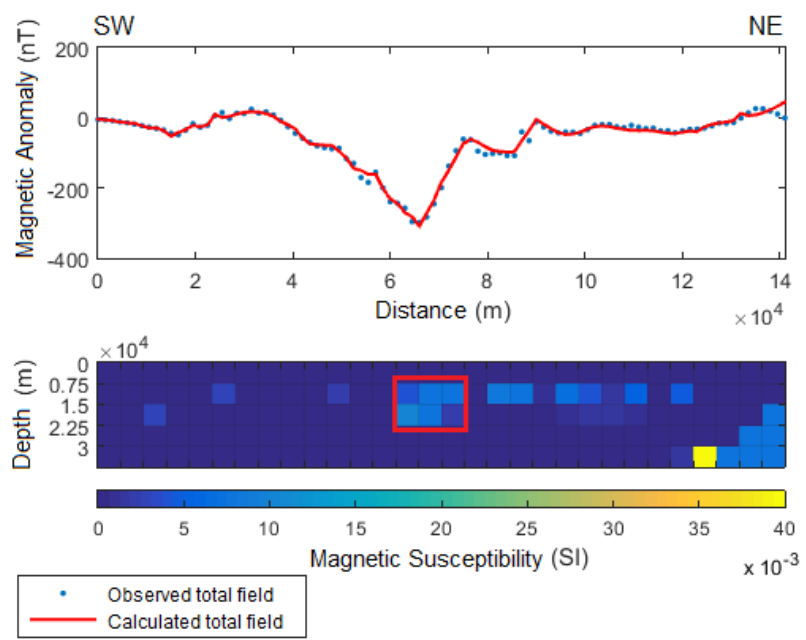

Figure 4: Result of the magnetic inversion for the L2 profile, referent to the Rio Coruripe source. 


\section{Pernambuco-Alagoas source}

For the inversion of the L3 profile referent to the Pernambuco-Alagoas source, 30 prisms were also inserted in the $\mathrm{X}$-direction and 5 prisms were inserted in the Z-direction, with a thickness of 5.500 meters for each prism. The maximum number of iterations was 20 , with a susceptibility contrast of 0.1 for each prism. The result of the inversion for the L3 profile is shown in figure 5, where a magnetic source, also highlighted by the red rectangle, was found at approximately 7.500 meters in depth, with a magnetic susceptibility of 0.0079584 (SI). The error between the calculated and observed data was $5.02 \%$. The result also shows that the source has an approximate rectangular shape.
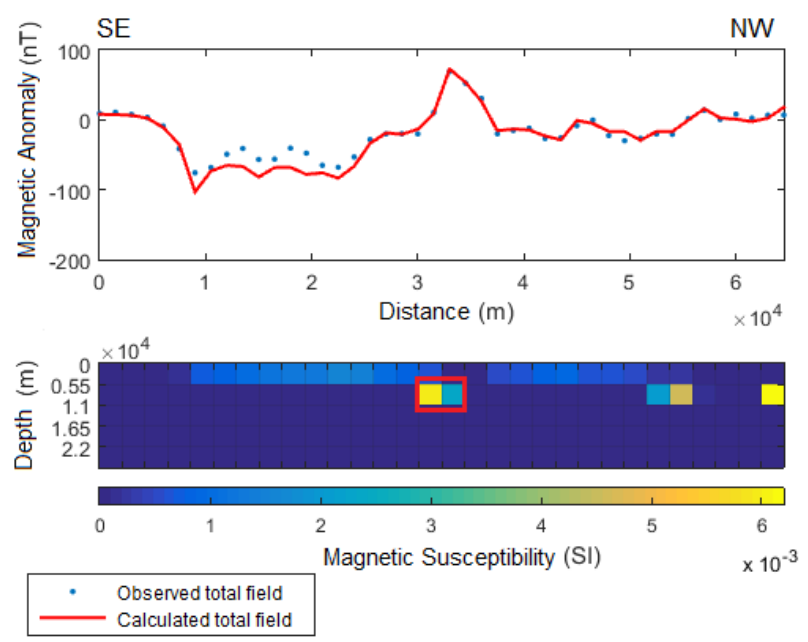

Figure 5: Result of the magnetic inversion for the L3 profile, highlighting the Pernambuco-Alagoas source.

For the inversion of the $L 4$ profile also referent to the Pernambuco-Alagoas source, 30 prisms were inserted along the $\mathrm{X}$-direction and 5 prisms were insert along the Z-direction, with a thickness of 6.000 meters and susceptibility contrast of 0.08 for each prism. The maximum number of iterations was also 20 . The result of the inversion for the L4 profile is shown in figure 6 , where a magnetic source was found at 9.000 meters in depth, with a magnetic susceptibility of 0.0076247 (SI). The error between the calculated and observed data was $4.04 \%$.

Thus, we can assume that the Pernambuco-Alagoas source is located between 7.500 and 9.000 meters in depth, being shallower than the Rio Coruripe source and with a rectangular shape, and has a magnetic susceptibility of approximately 0.0077 (SI). The Pernambuco-Alagoas source also outcrops into the surface, since we can also see that there are prisms with a smaller magnetic susceptibility above the source in figures 5 and 6 , that also indicates an enhancement of magnetic susceptibility until the depth found by the inversion.

To verify the information obtained in the magnetic inversion's results, gravity models were created, where the lithologies inserted were obtained according to the lithologies that outcrops in the region. The gravity data were acquired by the Nacional Agency of Petroleum
(ANP) and the GEOTERM SE-AL project, in which this work was developed, with a survey of 450 gravity stations.
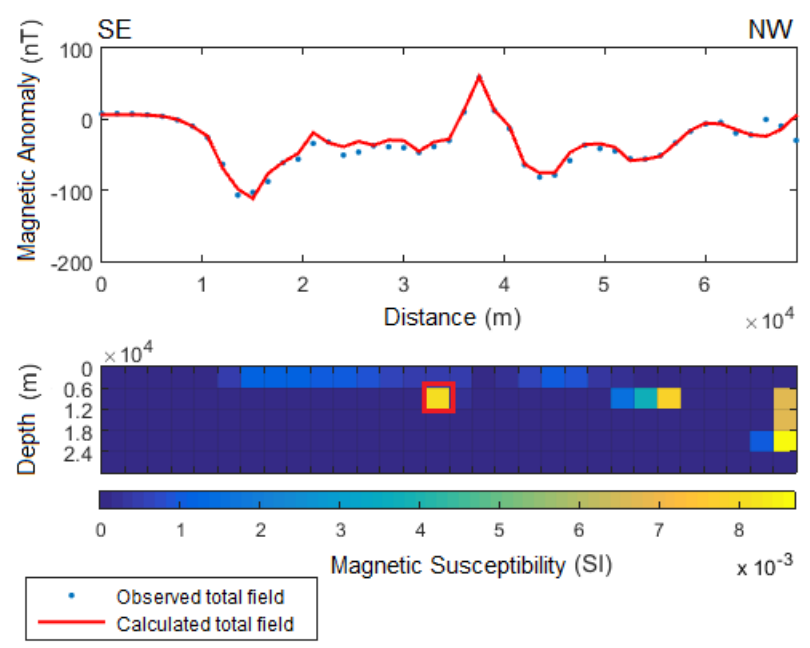

Figure 6: Result of the magnetic inversion for the L4 profile, referent to the Pernambuco-Alagoas source.

The profiles used for the gravity models were extracted from the residual bouguer anomaly map, show in figure 7 , where the L1 (Rio Coruripe source) and L3 (PernambucoAlagoas source) profiles are located in the same positions of the profiles used for the magnetic inversion shown in figure 1.

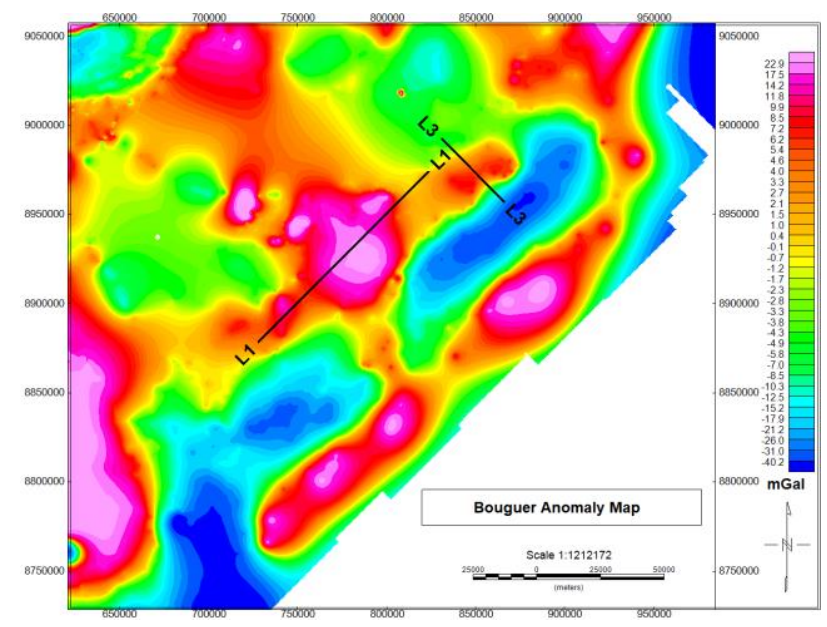

Figure 7: Residual bouguer anomaly map, with the profiles extracted for the gravity models.

Since the Rio Coruripe domain is formed by paragneisses and its basement is formed by granulite and amphibolite facies, the densities used were: paragneisses - 2.80 $\mathrm{g} / \mathrm{cm}^{3} ;$ granulite $-2.65 \mathrm{~g} / \mathrm{cm}^{3} ;$ amphibolite $-2.70 \mathrm{~g} / \mathrm{cm}^{3} ;$ sediments $-2.30 \mathrm{~g} / \mathrm{cm}^{3}$. In the gravity model shown in figure 8 , we can see that the Rio Coruripe source (a paragneiss) outcrops into the surface, with its narrower part at approximately 9.000 meters, its biggest lateral extension at approximately 15.000 meters and goes back to straighten again between 18.000 and 21.000 meters, which are the results found for this source's magnetic inversion. We can also see that the basement base was 
located at approximately $37.7 \mathrm{~km}$ and the sediments (shallower sources, that were previously considered as noise) goes down to approximately 709 meters, where the basement top is located, which are the results found by the spectral analysis. The Jirau do Ponciano dome was also modeled since the gravity profile passes on top of it, with a density of $2.8 \mathrm{~g} / \mathrm{cm}^{3}$.

Since the Pernambuco-Alagoas domain is formed by orthogneisses and high degree supracrustal units (granulite) intercalated by granites, the densities used for this source's gravity model were: orthogneiss - 2.80 $\mathrm{g} / \mathrm{cm}^{3}$; granite - $2.70 \mathrm{~g} / \mathrm{cm}^{3} ;$ granulite - $2.65 \mathrm{~g} / \mathrm{cm}^{3}$; sediments $-2.30 \mathrm{~g} / \mathrm{cm}^{3}$. As we can see in figure 9 , the Pernambuco-Alagoas source (an orthogneiss) outcrops into the surface, has a rectangular shape and is located between 7.500 and 9.000 meters in depth, as detected by the magnetic inversion. The basement base and top are located in the same depths found by the spectral analysis, although in some parts, the sediments go to a depth deeper than 709 meters, due to the fact that this profile passes through the sedimentary basin.

More magnetic inversions and gravity models were done for both sources and they can be found in the work written by ARAÚJO (2018), as well as all the data processing performed in the magnetic and gravity maps shown in figures 1 and 7 , and the results of the spectral analysis curves.

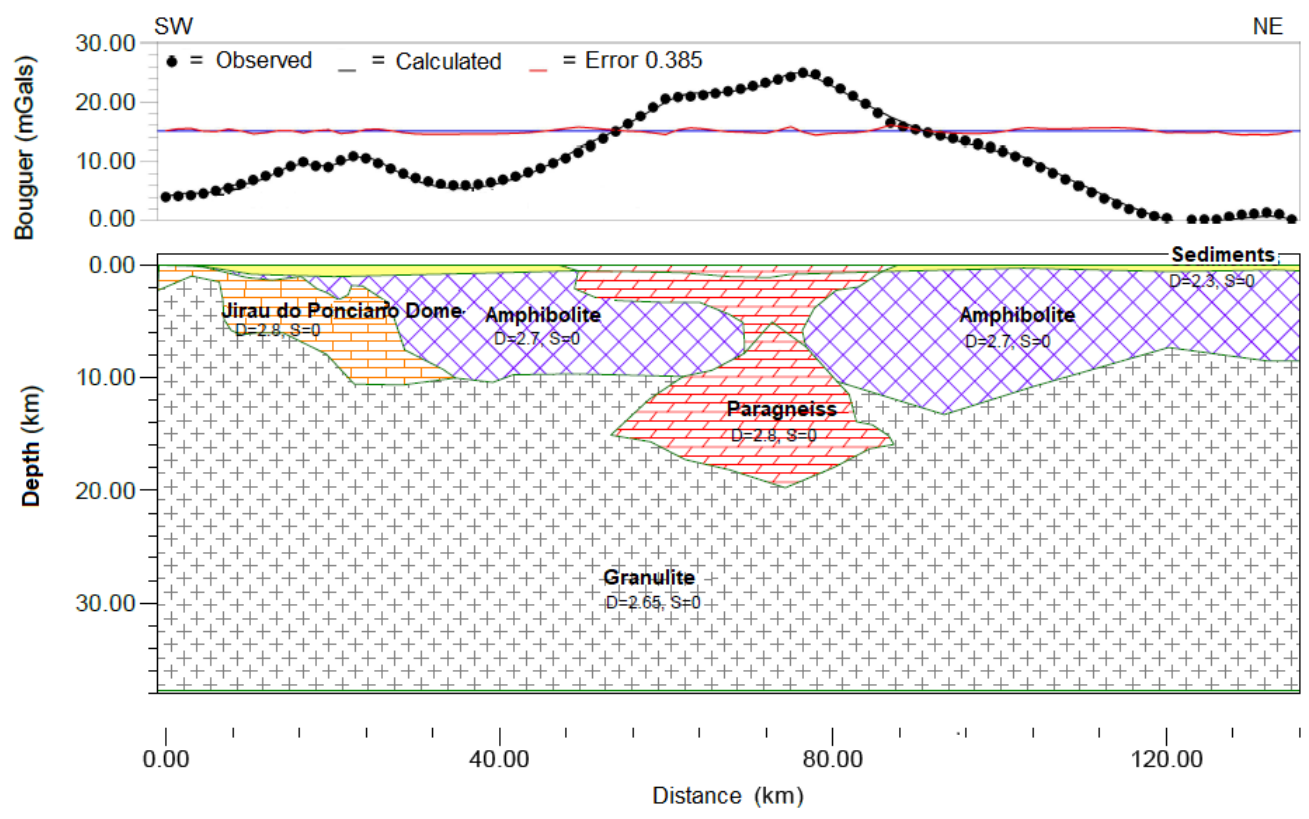

Figure 8: Gravity model of the L1 profile for the Rio Coruripe Source.
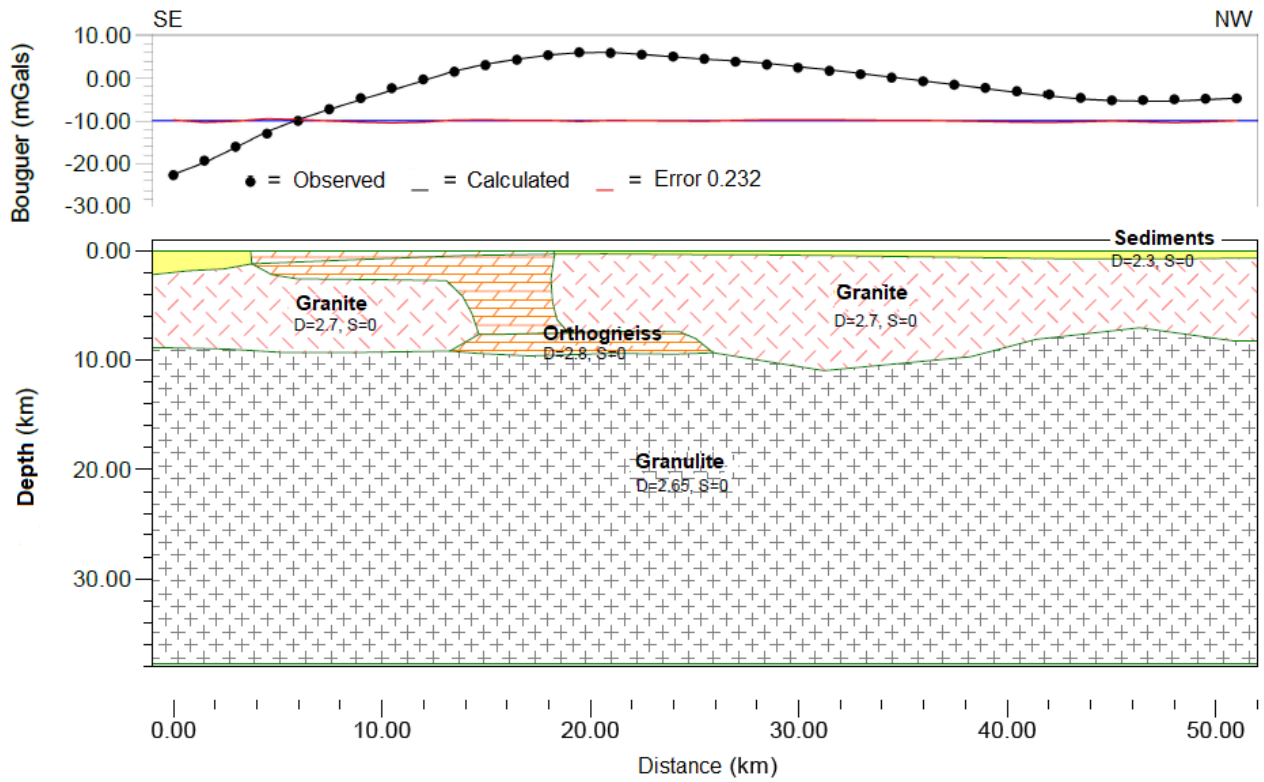

Figure 9: Gravity model of the $L 3$ profile for the Pernambuco-Alagoas source. 


\section{Conclusions}

The results of the magnetic inversions, main purpose of this work, were satisfactory, since the calculated data obtained by the inversions were well adjusted to the observed data. For the Rio Coruripe source, the inversion detected a body with a magnetic susceptibility of approximately 0.0079 (SI) between 9.000 and 21.000 meters in depth and that outcrops into the surface with a smaller magnetic susceptibility. In the PernambucoAlagoas domain, the inversion detected a source with a magnetic susceptibility of approximately 0.0077 (SI) between 7.500 and 9.000 meters in depth and that also outcrops into the surface with a smaller magnetic susceptibility.

The interpretation of the THG map was useful, because it provided geological information that helped understanding the location and directions of the sources, folds and shear zones in the region.

The spectral analysis was of extreme importance for this work, because it was able to find a depth for the basement base and top, which are located at $37.7 \mathrm{~km}$ and 709 meters, respectively.

All of these results were verified by the gravity models created, which located all the depths found by the magnetic inversion and spectral analysis.

\section{Acknowledgments}

- CPGG and LFNA, Federal University of Bahia.

- CPRM and ANP, for granting the data used in this work.

- GEOTERM SE-AL project, in which this work was developed.

- Geotec- Cenpes -Petrobras, Project 0050.0082543.139.

\section{References}

ARAÚJO, P. A. Inversão 2-D de dados magnéticos e modelagem gravimétrica para caracterização do embasamento adjacente à Bacia Sergipe-Alagoas. Trabalho de Graduação, Universidade Federal da Bahia, 2018.

BRITO NEVES, B. d.; SIAL, A.; RAND, H. and MANSO, V. The Pernambuco-Alagoas massif, northeastern Brazil, Revista Brasileira de Geociências, 12:240-250, 1982.

DOS SANTOS, R. A.; MARTINS, A. A. M.; DAS NEVES, J. P. e LEAL, R. A. Geologia e Recursos Mineirais do Estado de Sergipe, CPRM - Serviço Geológico do Brasil. Ministério de Minas e Energia. Secretaria de Minas e Metalurgia, 1998.

LAST, B. and KUBIK, K. Compact gravity inversion, Geophysics, 48(6):713-721, 1983.
MENDES, V. A.; LIMA, M. A. B.; DE MORAIS, D. M. F. e DE BRITO, M. d. F. L. Geologia e Recursos Mineirais do Estado de Alagoas, CPRM - Serviço Geológico do Brasil. Ministério de Minas e Energia. Secretaria de Minas e Metalurgia, 2017.

NEVES, S. P.; DA SILVA, J. M. R. and BRUGUIER, O. The transition zone between the Pernambuco-Alagoas domain and the Sergipano Belt (Borborema Province, NE Brazil): Geochronological constraints on the ages of deposition, tectonic setting and metamorphism of metasedimentary rocks, Journal of South American Earth Sciences,72:266-278,2016.

STOCCO, S.; GODIO, A. e SAMBUELLI, L. Modelling and compact inversion of magnetic data: A Matlab code, Computers \& Geosciences, 35(10):2111-2118, 2009.

TALWANI, M.; WORZEL, J. L. e LANDISMAN, M. Rapid gravity computations for two-dimensional bodies with application to the mendocino submarine fracture zone, Journal of geophysical research, 64(1):49-59, 1959. 